\title{
ANTIFIBRINOLYTIC ACTIVITY IN NORMAL PREGNANCY
}

\author{
BY \\ J. J. BIEZENSKI * \\ From the Rotunda Hospital Laboratory, Dublin
}

(RECEIVED FOR PUBLICATION OCTOBER 2, 1959)

\begin{abstract}
It is found that serum antifibrinolytic activity is inhibitory both to the spontaneous fibrinolytic activity and to the activity of streptokinase-activated plasminogen.

The titres of serum antiplasmin activity during gestation, labour, and the puerperium are all of the same order and do not differ from those in non-pregnant women. The marked decrease in the spontaneous fibrinolytic activity in late pregnancy and labour is therefore due to an actual reduction in the circulating active lytic enzyme and is not associated with a change in the antifibrinolytic activity.
\end{abstract}

The fibrinolytic activity of plasma depends upon the activation of the inert plasminogen into an active plasmin, and is brought about naturally by the action of activators in the circulating blood and in the tissues (Astrup, 1956a). It can also be induced by means of such substances as streptokinase, chloroform, and many others (Astrup, 1956b). In certain abnormal circumstances, e.g., after an injection of adrenaline (Biggs, Macfarlane, and Pilling, 1947) or in the post-operative period (Truelove, 1952), a considerable degree of fibrinolytic activity can be detected. Under normal conditions, however, plasma shows little, if any, spontaneous fibrinolytic activity (Macfarlane and Biggs, 1946) unless special precautions are observed. When blood is cooled down to $0^{\circ} \mathrm{C}$. immediately after collection and assayed within 15 minutes, about $90 \%$ of people show spontaneous fibrinolytic activity (Fearnley and Tweed, 1953) though the degree of that activity is not very marked (Biezenski and Moore, 1958).

It was shown in a previous communication (Biezenski and Moore, 1958) that the spontaneous fibrinolytic activity of plasma in normal pregnancy, as assessed by the ice-cold technique, varies according to the stage of pregnancy. In the first 15 weeks of gestation the activity is present in about $95 \%$ of cases. This corresponds closely to the value obtained in non-pregnant women. As pregnancy progresses, however, there occurs a gradual reduction in incidence till in the last few weeks and in labour the activity can be demonstrated in only about $10 \%$ of cases. There is a rapid return to a normal incidence in the *Present address: Department of Haematology, Montefiore
Hospital, New York. immediate puerperium. The assessments of the degree of fibrinolysis in patients where lysis was demonstrable have similarly shown a decrease in late pregnancy and in labour.

The plasma fibrinolytic activity depends further on the inhibitory action of the antifibrinolytic system. The presence in plasma of substances which inhibit lysis has been known for many years. More recently Norman (1958) postulated the presence of two antifibrinolytic factors and Ratnoff, Lepow, and Pillemer (1954) found in serum three specific substances inhibitory to plasmin.

Irrespective, however, of the mechanism of the inhibition or of the possible multiplicity of its components, the higher the degree of the total antifibrinolytic activity the lower the level of the lytic activity. The present study is an attempt to find out whether the decrease in the fibrinolytic activity in late pregnancy and labour is due to a high antifibrinolytic titre.

\section{Method}

The antifibrinolytic activity of blood is assessed by observing the effect of serum on plasmin in a fibrinogen-thrombin system. When plasma is recalcified all the spontaneous fibrinolytic activity is adsorbed on to the clot (Fearnley, 1953). Antifibrinolytic activity, however, remains unaffected as shown by Grob (1949), who found the same degree of antifibrinolytic activity in plasma as in serum.

The quantitative assessment is based on Shulman's observation that the amount of fibrinolytic enzyme inhibited is proportional to the amount of serum added (Shulman, 1952a). A series of dilutions of plasmin is acted upon by aliquots of serum. The alternative method of adding aliquots of plasmin to 
varying dilutions of serum (Bozzo, Piomelli, and Schettini, 1956) did not in my hands give uniform results and was abandoned.

It will be noted that observations on the fibrinolytic activity in pregnancy (Biezenski and Moore, 1958) were made by assessing the spontaneous lytic activity. This may well differ with regard to the inhibitory system from the plasmin activity. For example, Biezenski and Moore (1959) observed, as did also Jacobsson (1955a), that, in distinction from plasmin, spontaneous fibrinolysin does not attack fibrinogen. Therefore, a series of preliminary experiments was carried out which consisted in adding $0.1 \mathrm{ml}$. of serum to doubling dilutions of plasma containing proved spontaneous fibrinolytic activity. The activity was inhibited in all cases, showing that serum contains an inhibitor of the spontaneous fibrinolytic system.

Reagents. -The following were used :

Fibrinogen.-A solution of human fibrinogen was prepared by the method previously described (Biezenski and Moore, 1958). It was used fresh or freeze-dried and reconstituted in buffer to a concentration of $250 \mathrm{mg}$. \%.

Veronal Buffer.- $p \mathrm{H} 7.35$.

Thrombin.-Thrombin (Roche) was dissolved in water to a concentration of 10 units $/ \mathrm{ml}$.

Plasmin.-Plasminogen powder was prepared from human plasma fraction III* by Cliffton and Cannamela's modification (Cliffton and Cannamela, 1953) of Kline's method (Kline, 1953). The powder was weighed and activated by streptokinase ("varidase" $\dagger$ ) by the method of Fishman and Kline (1956). The solution of plasmin was stored frozen at $-10^{\circ} \mathrm{C}$. in $1 \mathrm{ml}$. amounts in the concentration of $60 \mathrm{mg} . \%$. It was thawed immediately before use and the dilutions were adjusted with buffer.

All nitrogen determinations were carried out by Conway's microdiffusion technique.

Technique.-Twelve plasmin dilutions of the original concentration of $60 \mathrm{mg}$. \% were prepared by the addition of buffer: $1 / 30,1 / 60,1 / 90,1 / 120$, $1 / 150,1 / 180,1 / 210,1 / 240,1 / 270,1 / 300,1 / 330$, and $1 / 360$. Of the $1 / 30$ dilutions, $0.1 \mathrm{ml}$. was placed in a 4 in. $\times \frac{3}{8}$ in. glass tube; $0.1 \mathrm{ml}$. of the $1 / 60$ dilution was placed in the second tube and so on. Blood was obtained by venipuncture into a glass tube without any anticoagulant. Serum was separated from the spontaneously clotted blood by centrifugation for 15 minutes at 3,000 r.p.m. and diluted $1 / 20$ with buffer. Then $0.1 \mathrm{ml}$. of the diluted serum was added to all the plasmin tubes which were incubated for 10 minutes in a $37^{\circ} \mathrm{C}$. water-bath. (Prolongation of the incubation time up to half an hour did not appreciably alter the results.) At the end of 10 minutes

*Donated by the American National Red Cross and obtained through the courtesy of Mr. Tillman D. Gerlough, of E. R. Squibb and Sons, New Brunswick. N.J.

tCommercial Varidase (Lederle) obtained through the courtesy of Mr. Collins, of the Dublin Branch of the American Cyanamid Company, Lederle Laboratories.

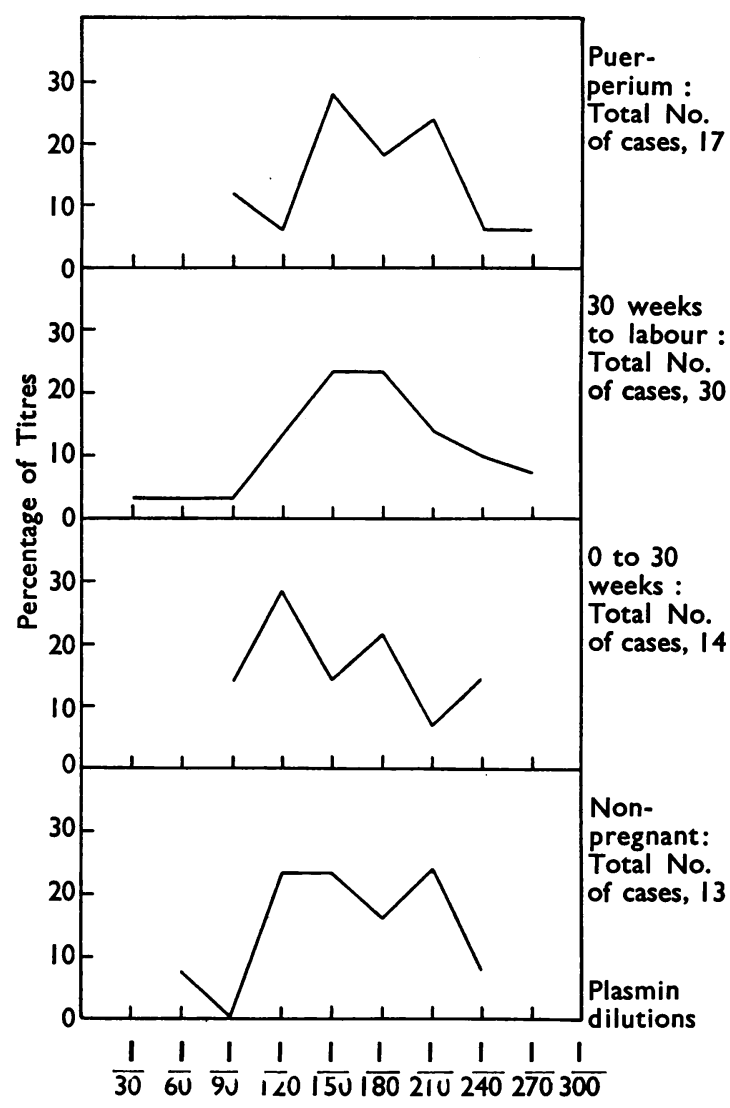

FIG. 1.-Distribution of titres of antifibrinolytic activity in normal pregnancy.

$0.2 \mathrm{ml}$. of fibrinogen solution and $0.2 \mathrm{ml}$. of thrombin were added to each tube in quick succession. The mixtures clotted in no more than 30 seconds. The formation of the clot in each tube was checked and the tubes were left in the water-bath for exactly 30 minutes. The tubes were then inspected for the preservation of clot.

The antifibrinolytic titre of serum was expressed in terms of the lowest dilution of plasmin inhibited.

The results were uniform and no zonal phenomenon was observed. Control experiments with normal saline instead of serum resulted in the absence of clot in all the tubes.

All the pregnant and non-pregnant women examined were normal.

\section{Results}

The patients were divided into four groups: non-pregnant, 0 to 30 weeks' gestation, 30 weeks' to labour inclusive, and the first week of the puerperium. In all, 74 patients were examined.

It can be seen from Fig. 1 that the distribution of titres within each group follows a fairly 
symmetrical pattern. Each group presents a peak of incidence where most cases are concentrated with an even fall on either side of the peak. This marked concentration of titres is even more obvious when one realizes how small are the differences between successive plasmin dilutions. The range of titres is also very similar in all the groups, though the " 30 weeks' to labour" group shows a slightly wider range than is seen in the other groups. This, however, is thought to be due to the larger number of determinations carried out.

Most titres of the non-pregnant series fall between the $1 / 120$ and the $1 / 210$ dilutions of plasmin ; those of the " 0 to 30 weeks' gestation" between $1 / 120$ and $1 / 180$ dilutions, as do those of the " 30 weeks' to labour" group. The titres of the puerperal group fall between the 1/150 and the $1 / 210$ dilutions. There is thus a marked similarity between all the groups which is further substantiated by the fact that the average titre value for each series is about the same, i.e., between the $1 / 150$ and the $1 / 180$ dilutions.

\section{Discussion}

Several reports on the antifibrinolytic activity in normal human plasma can be found in the literature (Shulman, 1952b ; Bozzo et al., 1956). It is interesting that irrespective of the method used they present similar results which are further confirmed by my findings. The differences in the level of the activity in normal people are insignificant though sporadic cases may show a marked increase. Furthermore, the activity is not influenced by sex or food ingestion and remains the same for the same individual for prolonged periods of time (Shulman, 1952a).

On the other hand, higher levels were reported in many abnormal states such as nephrosis (Jacobsson, 1955b), pernicious anaemia, pneumonia, and others (Guest, Daly, Ware, and Seegers, 1948), but in patients suffering from rheumatoid arthritis no departure from normal was noted (Hammarsten and Jonsson, 1954). Higher levels were found in "platelet-rich plasma" and lower than normal in thrombocytopenia (Stefanini and Murphy, 1956).

These observations show that the titre of antifibrinolytic activity throughout pregnancy, labour, and the puerperium is almost the same and, furthermore, does not differ from that found in non-pregnant women. Although it could be argued that inasmuch as uncomplicated pregnancy is a physiological process there is no reason for the antifibrinolytic activity to undergo any change, one must not forget that serum of pregnant women contains large amounts of substances which have been reported to affect the activity at least in vitro and in the animal. Thus Ungar and Damgaard (1951) found an increase in the antifibrinolytic activity in rats after injections of A.C.T.H. and cortisone, but their results were not confirmed in man by Cliffton (1952).

An increase in the antifibrinolytic activity after ingestion of butter and eggs was reported by Greig and Runde (1957). They attributed this effect to the high content of beta-lipoproteins in those foods, and it has been shown that betalipoproteins are much increased in pregnancy (Smith, de Alvarez, and Forsander, 1959).

The influence of high fibrinogen levels, as found throughout pregnancy, is not clear either. Shulman (1952a) reported that in vitro the fibrinolytic activity decreases with the increase in the amount of fibrinogen present whereas Norman (1958) found that in the fibrinogen-lysin-antilysin system the inhibitor competes with the fibrinogen substrate for the lytic enzyme so that with higher fibrinogen concentrations one would expect higher antifibrinolytic levels.

Since it is obvious from the results that there is no increase in the antifibrinolytic activity in late pregnancy and labour, the low titre of spontaneous fibrinolysis in those states must be due to an actual reduction in the circulating lytic enzyme. This may be due to an appearance in the plasma of those patients of an inhibitor which specifically inhibits the activation of plasminogen but which does not inhibit the active lytic enzyme and which, therefore, is not apparent in the experiments carried out. Or, again, it is possible that the plasma of women approaching term becomes deficient in that component of the lytic system which is responsible for the generation of spontaneous fibrinolytic activity.

I am the recipient of a whole-time grant from the Medical Research Council of Ireland to which I am much indebted. I wish to express my sincerest thanks and gratitude to Dr. H. C. Moore, Director of the Rotunda Hospital Laboratory, for his invaluable advice and assistance. I also wish to thank the Master and the medical and nursing staffs of the Rotunda Hospital for their willing co-operation.

\section{REFERENCES}

Astrup, T. (1956a). Blood, 11, 781.

(1956b). Lancet, 2, 565.

Biezenski, J. J., and Moore, H. C. (1958). J. clin. Path., 11, 306. - (1959). J. Obstet. Gynaec. Brit. Emp., 66, 82.

Biggs, R., Macfarlane, R. G., and Pilling, J. (1947). Lancet, 1, 402. 
Bozzo, A., Piomelli, S., and Schettini, F. (1956). Riv. Ist. sieroter. ital., 31, 362.

Cliffton, E. E. (1952). J. Lab. clin. Med., 39, 105.

and Cannamela, D. (1953). J. appl. Physiol., 6, 42.

Fearnley, G. R. (1953). Nature (Lond.), 172, 544.

and Tweed, J. M. (1953). Clin. Sci., 12, 81.

Fishman, J. B., and Kline, D. L. (1956). Proc. Soc. exp. Biol. (N.Y.), $91,323$.

Greig, H. B. W., and Runde, I. A. (1957). Lancet, 2, 461.

Giob, D. (1949). J. gen. Physiol., 33, 103.

Guest, M. M., Daly, B. M., Ware, A. G., and Seegers, W. H. (1948). J. clin. Invest., $27,793$.

Hammarsten, G., and Jonsson, E. (1954). Acta med. scand., 147, 363 .
Jacobsson, K. (1955a). Scand. J. clin. Lab. Invest., 7, Suppl. 14, p. 9. (1955b). Ibid., 7, Suppl. 14, p. 58.

Kline, D. L. (1953). J.biol. Chem., $204,949$.

Macfarlane, R. G., and Biggs, R. (1946). Lancet, 2, 862.

Norman, P. S. (1958). J. exp. Med., 108, 53.

Ratnoff, O. D., Lepow, I. H., and Pillemer, L. (1954). Bull. Johns Hopk. Hosp., 94, 169.

Shulman, N. R. (1952a). J. exp. Med., 95, 571.

(1952b). Ibid., 95, 593.

Smith, E. K., Alvarez, R. R. de, and Forsander, J. (1959). Amer. J. Obstet. Gynec., 77, 326.

Stefanini, M., and Murphy, I. S. (1956). J. clin. Invest., 35, 355.

Truelove, S. C. (1952). Clin. Sci., 11, 107.

Ungar, G., and Damgaard, E. (1951). J. exp. Med., 93, 89. 